\section{Bagging Apple Fruit for Codling Moth Control in Western Montana}

\author{
Rachel Leisso ${ }^{1}$, Bridgid Jarrett ${ }^{1}$, Katrina Mendrey ${ }^{1}$, and \\ Zachariah Miller ${ }^{1}$
}

AdDitional INDEX wORDs. Cydia pomonella, integrated pest management, Malus domestica, urban agriculture

Summary. Codling moth (Cydia pomonella) is a major insect pest of apple (Malus domestica). If unmanaged, then codling moth can infest nearly all apples in an orchard, where the flesh-tunneling larva leave frass-laden tracks in the fruit. Insecticide-based management requires accurate application timing (typically based on adult moth and/or degree-day monitoring) and multiple spray applications. Both the season-long commitment to codling moth monitoring and management and limited familiarity with insecticides, application tools, and proper application procedures can prevent a small-scale or backyard grower from effectively limiting fruit damage. In addition, an increasing segment of growers is interested in nonchemical alternatives. Bagging fruitlets early in the season could be a simple and effective method of codling moth management for this subset of growers. At our research orchard in Corvallis, MT, we tested a method combining fruit thinning and bagging using plastic bags the first season and nylon bags the second season. Plastic bags reduced the incidence of codling moth damage to fruit from $34 \%$ to $10 \%$, but european earwig (Forficula auricularia) frass, which was found in more than $50 \%$ of plastic-bagged apples, made harvesting the fruit unappealing. We tested nylon fruit bags during the second year of the study. These bags did not significantly reduce the incidence of codling moth. Both the soluble solids content and titratable acidity were higher in unbagged fruit during the second year of the study, whereas color measurements indicated bagged fruit were greener on the shaded side of the fruit. Failure of the nylon bags may have been attributable to eggs laid before bagging, eggs laid or larva burrowing through bagging, or improper bag application methods. Further research could assess whole-tree bags, the addition of rubber bands or twist ties when applying nylon bags, pretreatment of fruit with horticulture oil, and/or dipping nylon bags in kaolin clay before application; however, these steps add time and increase costs, which may discourage the small-scale fruit grower. Overall, results indicate that fruit bagging holds promise for codling moth management; however, further work is needed to optimize the methodology.

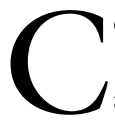
odling moth (Cydia pomonella) is a major insect pest of apple (Malus domestica) almost everywhere the fruit is grown. In Montana, frass-filled exit holes left by codling moth larva (strikes) were apparent on more than $50 \%$ of apple fruit in late summer (August or September) in some orchards west of the continental divide (Leisso et al., 2020). Management of this pest in commercial orchards requires tracking degree-days, monitoring codling moth life stages, and multiple insecticide applications (Jones et al., 2013; Murray and Alston, 2020). This level of attuned and season-long management may be excessive for small-scale, noncommercial growers who are typically not as well-versed as commercial fruit growers in safe and environmentally responsible insecticide application, nor as familiar with the codling moth life cycle and appropriate insecticide timing. A simpler management method with potential appeal to small-scale or noncommercial growers combines fruit thinning and bagging early during the season to protect fruits from adults laying eggs on the fruit. Complete prevention of adults laying eggs on fruit is difficult because adults typically emerge near the time of full bloom; therefore, other methods to reduce overall populations are advised (for example, removing and destroying fallen fruit, trunk banding) (Murray and Alston, 2020). Fruit bagging can reduce the need for spraying and result in a high percentage of undamaged fruit (Bentley and Viveros, 1992) and, in many cases, enhance other aspects of fruit quality (Buthelezi et al., 2021). Information is limited, however. A recent review of fruit bagging strategies called for more research because it discovered a dearth of published information pertaining to codling moth (Buthelezi et al., 2021). An extension guide by Alfuth (2019) indicates plastic bags can be effective but does not indicate the level of control. Bessin and Hartman (2019) combined Japanese apple bags or paper bags with dormant oil and two early-season insecticide applications to substantially reduce codling moth-damaged fruit (along with several diseases); however, avoiding spray applications altogether would be simpler and preferred by some backyard growers.

The objectives of this study were to evaluate fruit bagging as a strategy for mitigating codling moth damage and to determine the effects of bags on fruit quality. Because labor and time constraints are concerns for all fruit growers, we also report the time to thin and bag fruit according to each type of bag.

\section{Materials and methods}

For both years of the study, 17 trees in the middle row of a 38 -tree 'Cortland' apple block at Montana State University Western Agricultural Research Center, Corvallis, MT (lat. $46^{\circ} 19^{\prime} 45.5 \mathrm{~N}$, long. $114^{\circ} 5^{\prime} 7.4 \mathrm{~W}$ ) were used. Fruit bagging dates and information are detailed in Table 1 . We selected fruit on lower branches that did not require ladders to reach for crew safety reasons. Time spent bagging and thinning and bags remaining at harvest were recorded both years. Insecticides were not applied to the

\begin{tabular}{llll}
\hline $\begin{array}{l}\text { Units } \\
\text { To convert U.S. to SI, } \\
\text { multiply by }\end{array}$ & U.S. unit & SI unit & $\begin{array}{l}\text { To convert SI to U.S., } \\
\text { multiply by }\end{array}$ \\
\hline 10 & $\%$ & $\mathrm{~g} \cdot \mathrm{L}^{-1}$ & 0.1 \\
2.54 & inch(es) & $\mathrm{cm}$ & 0.3937 \\
0.0254 & $\mathrm{mil}(\mathrm{s})$ & $\mathrm{mm}$ & 39.3701 \\
28.3495 & $\mathrm{Oz}$ & $\mathrm{g}$ & 0.0353 \\
$\left({ }^{\circ} \mathrm{F}-32\right) \div 1.8$ & ${ }^{\circ} \mathrm{F}$ & ${ }^{\circ} \mathrm{C}$ & $\left({ }^{\circ} \mathrm{C} \times 1.8\right)+32$
\end{tabular}


Table 1. Approximate apple fruit size, bagging dates, codling moth degree-days (CDD), estimated adult codling moth flight at bagging, time required to thin and bag fruit, and percent fruit damaged by codling moth according to bag type and year. The adult moth presence as indicated by biofix and the estimated proportion of adult emergence (flight) at the time of bagging implies that eggs may have been laid on fruit before bagging. Six fruit and 12 fruit per each of the 17 trees were bagged in 2019 and 2020, respectively. We also noted earwig frass in the fruit stem bowl in 2019.

\begin{tabular}{|c|c|c|c|}
\hline & \multicolumn{2}{|c|}{ Plastic bags (2019) } & Nylon bags (2020) \\
\hline Fruit size at bagging & \multicolumn{2}{|c|}{ Diameter of $\approx 1.5 \mathrm{~cm}(0.59 \mathrm{inch})$} & Diameter of $\approx 1.5 \mathrm{~cm}$ \\
\hline Bagging date & \multicolumn{2}{|c|}{5 June 2019} & 1 June 2020 \\
\hline CDD since biofix on bagging date ${ }^{\mathrm{z}}$ & \multicolumn{2}{|c|}{170} & 130 \\
\hline Estimated adult moth flight $\mathrm{t}^{\mathrm{y}}$ & \multicolumn{2}{|c|}{$27 \%$} & $20 \%$ \\
\hline Thinning and bagging time per fruit & \multicolumn{2}{|c|}{$1 \mathrm{~min}$ and $33 \mathrm{~s}$} & $1 \mathrm{~min}$ and $7 \mathrm{~s}$ \\
\hline \multirow[b]{2}{*}{ Treatment } & \multicolumn{3}{|c|}{ Mean \pm SE $(\%)$} \\
\hline & $\begin{array}{c}\text { Fruit with at least } \\
\text { one codling moth strike }\end{array}$ & $\begin{array}{l}\text { Earwig frass } \\
\text { in stem bowl }\end{array}$ & $\begin{array}{c}\text { Fruit with at least one } \\
\text { codling moth strike }\end{array}$ \\
\hline Bagged & $10.6 \pm 3.7 b^{x}$ & $53.1 \pm 7.4^{\mathrm{w}}$ & $18.3 \pm 4.0$ \\
\hline Unbagged & $34.9 \pm 9.8 \mathrm{a}$ & Visual estimate: $<5 \%$ & $21.6 \pm 2.7$ \\
\hline$P$ & 0.0002 & Not applicable & 0.3312 \\
\hline
\end{tabular}

${ }^{\mathrm{z}}$ Biofix defined as two moths caught two nights in a row in a codlemone lure (T3111; Trécé, Adair, OK) baited pheromone trap (Pherocon III Orange Delta Trap; Trécé). Biofix dates were 15 May 2019 and 15 May 2020. Codling moth degree-days are per USPest.org using the online app model called "codling moth v2 (Knight 2007)" (Knight, 2014).

'Based on Appendix 1, Table 6 in Beers et al. (1993).

${ }^{\mathrm{x}}$ Means followed by a different letter in a column are statistically different according to Wald's chi-square test $(P<0.05)$.

${ }^{w}$ No statistics performed: very few unbagged fruits had earwig frass and no official count was performed.

bagging trial row; however, they were applied to adjacent rows both years.

In 2019 , low-density polyethylene (plastic) bags measuring $61 / 2 \times 57 /$ 8 inches (width $\times$ height) (Ziploc sandwich bags; SC Johnson, Racine, WI) were purchased $(\$ 0.02$ each retail cost at a local store) and prepared by cutting off the corners to prevent moisture buildup (Alfuth, 2019). The bagging treatment involved thinning six fruitlet clusters per tree to a single fruitlet that

Received for publication 12 Mar 2021. Accepted for publication 19 May 2021.

Published online 23 June 2021.

${ }^{1}$ Department of Research Centers, Montana State University Western Agricultural Research Center, 580 Quast Lane, Corvallis, MT 59828

This project was supported by Montana Department of Agriculture Specialty Crop Block Grant AM180100XXXG047. We thank Montana State University Western Agricultural Research Center staff Chase Anderson, Haydon Davis, Amy Darling, Alex Hoogland, Kyrstan Hubbel, Aidan Kendall, Frances Rafferty, Rebecca Richter, Kierstin Schmitt, Olivia Soller, and Andrea Ziolkowski, and Montana State University Extension personnel Sandy Perrin and Patrick Mangan for their contributions to this project. We also thank the HortTechnology editors and reviewers for their helpful guidance and revisions during the publication process.

Mention of a trademark, proprietary product, or vendor does not constitute a guarantee or warranty of the product by the U.S. Department of Agriculture and does not imply its approval to the exclusion of other products or vendors that also may be suitable.

R.L. is the corresponding author. E-mail: rachel. leisso@montana.edu.

This is an open access article distributed under the CC BY-NC-ND license (https://creativecommons. org/licenses/by-nc-nd/4.0/)

https://doi.org/10.21273/HORTTECH04848-21 had a diameter of $\approx 1.5 \mathrm{~cm}$. A prepared plastic bag was slipped over each remaining fruitlet, sealed, and stapled on either side of the stem. For the control treatment, six additional fruit clusters were thinned and marked with flagging tape measuring $l$ inch wide $x$ 1 mil thick (green plastic flagging tape; Empire, Mukwongo, WI). The flagging tape length varied based on the amount needed to tie on a branch. Fruit were harvested on 2 Oct. 2019, after freezing temperatures (as low as $23{ }^{\circ} \mathrm{F}$ ). Data collected for the bagged fruit included the presence of codling moth fruit strikes and the presence of european earwig (Forficula auricularia) frass, typically in the stem bowl (the indentation surrounding the fruit stem). The latter was unexpected but sufficiently common to warrant documentation. Because of heavy self-thinning and the loss of flagging tape for many thinned clusters, all unbagged fruit were counted and assessed for codling moth strikes as the control.

In 2020, we used nylon mesh bags to eliminate the problem of moisture collection and earwig issues observed during the plastic bag trial. Heavy-duty nylon bags (style \#1040-heavy weave; Maggot Barriers, Gloucester, MA) were purchased $(\$ 0.10$ each retail price as purchased online). Bags were secured by gathering and tying the ends of the nylon tube-shaped bag around the stem ( 12 bags per tree). For the control treatment, the remaining clusters on the tree were hand-thinned to one fruitlet per cluster. Because of forecasted frost, fruit were harvested on 30 Sept. 2020 , and pooled into bins according to treatment. Forty fruit were selected at random from each bin to evaluate maturity. Fruit weight (grams) and surface color were recorded for all fruit. The peel color on red and green sides of the fruit were evaluated with a diffuse reflectance accessory (DRA) (Cary 60 DRA; Agilent Technologies, Santa Clara, CA) connected using a fiberoptic cable to a spectrophotometer (Cary 60 ultraviolet-Vis; Agilent Technologies) and recorded as lightness, chroma, and hue (Color App; Agilent Technologies). Then, 20 fruit for each treatment were cut in half for a starchiodine test, which was performed and the results were rated according to the Cornell scale (from 1 to 8) (Blanpied and Silsby, 1992). Iodine-stained portions and cores were removed before fruit were processed in a juicer (model E-1188 Jack LaLanne's Power Juicer; Tristar Products, Fairfield, NJ). After juicing, a drop of juice from each fruit was analyzed to determine the soluble solids concentration (SSC) using a hand-held refractometer (model number HI96841; HANNA Instruments, Smithfield, RI); the $\mathrm{pH}$ and titratable acidity (TA) were assessed with a potentiometric titrator (model AT1102; Hach, Loveland, CO) equipped with 
an autosampler (AS1000; Hach) connected to a $\mathrm{pH}$ electrode (IntelliCAL PHC281 pH Ultra Refillable pH electrode; Hach). Juice samples were titrated to a $\mathrm{pH}$ of 8.2 with $0.25 \mathrm{M}$ sodium hydroxide $(\mathrm{NaOH})$. Results are expressed in grams of malic acid per liter of solution.

Data were analyzed with the SAS statistical package (version 9.4; SAS Institute, Cary, NC). Proportions of codling moth-damaged fruit were analyzed with PROC LOGISTIC, cumulative logit model, and Fisher's scoring optimization technique; the Wald chisquare is reported. Fruit weight, $\mathrm{pH}$, TA, SSC, and color were analyzed with PROC GLM. Assumptions of normality were assessed using the Shapiro-Wilk test performed with PROC UNIVARIATE. When testing several transformations did not correct data to meet the assumption for normality, the nonparametric Kruskal-Wallis test was performed. Homogeneity of variance was tested using Levene's test. Tukey's post hoc test was used to establish the means separation when PROC GLM models were significant.

\section{Results}

In 2019, the cluster thinning and plastic bagging time required an average of 1 min and 33 s per fruit; however, in 2020, similar procedures with the nylon bags required $1 \mathrm{~min}$ and $7 \mathrm{~s}$ (Table 1). Plastic bagging reduced the incidence of codling moth from 35\% of control fruit to $11 \%$, but $53 \%$ of bagged fruit had earwig frass in the stem bowl (the indentation surrounding the fruit stem). There was no obvious damage from the earwigs. In 2020 , the nylon bagging of the fruit did not reduce the incidence of codling moth strikes. Nylon bagging affected fruit quality; the SSC was lower, TA was lower, and the fruit peel color on the nonred side of fruit (sometimes called "background color") was greener (Table 2 ).

In $2019,20 \%$ of the plastic bags were lost before harvest ( 81 remaining out of 102 placed). In 2020,30\% of the nylon bags were lost before harvest (142 remaining out of 204 placed).

Pictures from both years of the study are available online for public use via figshare (Leisso, 2021).

\section{Discussion}

The time required to thin and bag fruit was substantial. It was estimated to be between 40 and 60 fruit/h. Neither plastic sandwich bags nor nylon bags were completely effective methods for controlling codling moth. During the present study, plastic bags reduced codling moth strikes, but nylon bags did not. This does not necessarily indicate that nylon bags are less effective than plastic bags because bag types were assessed during different years. The presence of earwig frass in more than $50 \%$ of plastic bags made harvesting unappealing, although earwigs rarely damage apple fruit (Orpet et al., 2019), and their populations will vary among orchards. The codling moth degree-days and estimated life stages at the date of bagging (Table l) suggested that adults may have laid eggs on fruit before bagging. Avoiding codling moth egg-laying before bagging is difficult because adults typically begin emerging from pupae near the time of full bloom. Larvae also may have entered through slight gaps between the bag and fruit stem, or perhaps they burrowed their way through small holes in the nylon.

A previous study involving 'Granny Smith' apples thinned and paperbagged at golf ball size showed a reduced incidence of codling moth infestation to $0.4 \%$ and $1.3 \%$ compared with $2.5 \%$ and $24.5 \%$ during the 2 years of the study; no difference in codling moth infestation was observed in fruit that were and were not thinned (Bentley and Viveros, 1992). Other apple insect control using bagging has been reviewed by Buthelezi et al., (2021).

Nylon bags affected fruit quality, as indicated by the SSC, TA, and background color. Bags could be removed several weeks before harvest to improve fruit color (Buthelezi et al., 2021). Neither bag type was salvageable for reuse during the following season; therefore, they are not suitable for growers interested in sustainability.

\section{Conclusions}

Enclosing $\approx 1.5$-cm-diameter apple fruitlets in plastic bags reduced codling moth damage to fruit, but the presence of earwig frass and moisture in the bag (despite cutting corners off the bags) made harvest unappealing. During a

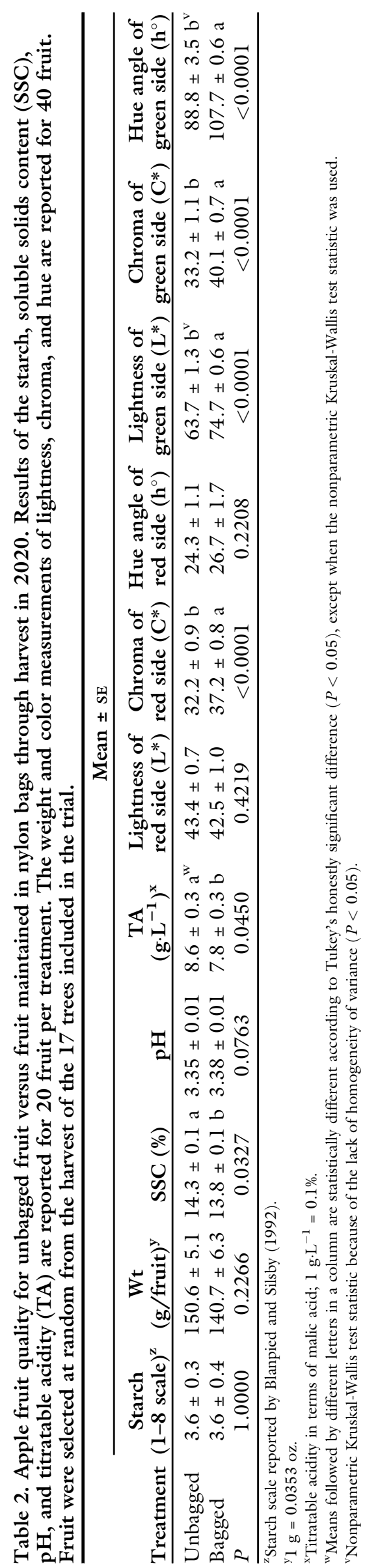


separate study year, nylon bags did not reduce codling moth damage to fruit, and the point of failure is unclear. Possible explanations include eggs laid on fruit before bagging, larvae entering fruit in slight gaps between the bag and the stem, or eggs laid on top of bags and larvae burrowing their way through the knit of the nylon into the fruit. Future research could include spritzing the fruit with horticultural mineral oil before applying bags (to kill any eggs), adding twist ties or rubber bands to secure bags, or dipping nylon bags in a kaolin clay solution before applying them. Additionally, whole-tree bags could be assessed.

\section{Literature cited}

Alfuth, D. 2019. Bagging apples for insect and disease control. Univ. WisconsinMadison Ext., Univ. Wisconsin Garden Facts XHT1268. 9 Apr. 2021. <https:// hort.extension.wisc.edu/files/2019/07/ Bagging_Apples_for_Insect_and_Disease_ Control.pdf $>$.
Beers, E.H., J.F. Brunner, M.J. Willett, and G.M. Warner. 1993. Orchard pest management. Good Fruit Grower, Yakima, WA.

Bessin, R. and J. Hartman. 2019. Bagging apples: Alternative pest management for hobbyists. Univ. Kentucky Coop. Ext. Serv., College Agr. Food Environ. Entfact218. 9 Apr. 2021. <https://entomology. ca.uky.edu/files/efpdf1/ef218.pdf>.

Bentley, W.J. and M. Viveros. 1992. Brown-bagging Granny Smith apples on trees stops codling moth damage. Calif. Agr. 46(4):30-32.

Blanpied, G.D. and K.J. Silsby. 1992. Predicting harvest date windows for apples. Cornell Coop. Ext. Bul. 221.

Buthelezi, N.M.D., T.P. Mafeo, and N. Mathaba. 2021. Preharvest bagging as an alternative technique for enhancing fruit quality: A review. HortTechnology 31:4-13.

Jones, V.P., R. Hilton, J. Brunner, W. Bentley, D.G. Alston, B. Barrett, R. Van Steenwyk, L. Hull, J. Walgenbach, W. Coates, and T. Smith. 2013. Predicting the emergence of the codling moth, Cydia pomonella (Lepidoptera: Tortricidae), on a degree-day scale in North America. Pest Manag. Sci. 69:1393-1398.

Knight, A.L. 2014. Adjusting the phenology model of codling moth (Lepidoptera: Tortricidae) in Washington state apple orchards. Environ. Entomol. 36: 1485-1493.

Leisso, R. 2021. Photo collection: Bagging apple fruit for apple codling moth control in western Montana. 8 Apr. 2021. <https://doi.org/10.6084/m9.figshare. c.5326763.vl>.

Leisso, R., C. Anderson, T. Novak, K. Mendrey, O. Soller, and Z. Miller. 2020. Montana surveys of codling moth damage to fruit 2019-2020. 9 Apr. 2021. <https:// doi.org/10.5061/dryad.pnvx0k6k7>.

Murray, M. and D. Alston. 2020. Codling moth in Utah orchards. Utah State Univ. Ext., Utah Plant Pest Diagnostic Lab. ENT-13-06. 9 Apr. 2021. <https://digital commons.usu.edu/extension_curall/880 $>$.

Orpet, R.J., D.W. Crowder, and V.P. Jones. 2019. Biology and management of european earwig in orchards and vineyards. J. Integr. Pest Manag. 10:1-9. 